\title{
Cervical polyp: evaluating the need of routine surgical intervention and its correlation with cervical smear cytology and endometrial pathology: a retrospective study
}

\author{
Bhabani Pegu, MD', Bheemanathi Hanuman Srinivas, MD², Thangamuthu Sri Saranya, MD', \\ Rajeswari Murugesan, MD³ , Smitha Priyadarshini Thippeswamy, MBBS ${ }^{1}$, Bhanu Pratap Singh Gaur, MD ${ }^{4}$ \\ Departments of ${ }^{1}$ Obstetrics and Gynecology, ${ }^{2}$ Pathology, ${ }^{3}$ Biostatistics, Jawaharlal Institute of Postgraduate Medical Education and Research (JIPMER); \\ ${ }^{4}$ Department of Community Medicine, Mahatma Gandhi Medical College and Research Institute (MGMCRI), Puducherry, India
}

\section{Objective}

To determine the frequency of premalignant and malignant lesions in cervical polyps in order to examine whether cervical polyps need to be removed routinely and also to appraise its association with cervical smear cytology and endometrial pathologies.

\section{Methods}

We retrospectively re-examined the hospital records of 299 cases over a period of 5 years. All patients were segregated into perimenopausal and postmenopausal groups according to their menopausal status. The groups were compared in terms of histological results of cervical polyp biopsy, endometrial pathologies, and cervical smear cytology. Pearson's $\chi^{2}$ test and Fisher's exact test were used for statistical analysis, and a $P$-value of $<0.05$ was accepted as statistically significant.

\section{Results}

In the histopathological reports of cervical polyps, premalignant lesions were found in $2 \%$ of cases, and only $0.3 \%$ of malignant lesion was observed in menopausal women. Subsequently, no malignancy was noted in cervical smear cytology for both groups. Premalignant and malignant lesions in endometrial histopathology findings were $1.33 \%$ and $0.66 \%$, respectively. There was a statistically significant association between the menopausal status of the patient and cervical smear cytology and endometrial pathology, but the histological findings were not statistically significant in relation to the symptomatic status of the patients.

\section{Conclusion}

As per the results, we strongly suggest the removal of all cervical polyps with subsequent histological review. The evaluation of cervical smear cytology prior to polypectomy can provide information about its malignancy potential. We believe that along with cervical polypectomy, endometrial sampling should be recommended, especially for postmenopausal women.

Keywords: Cervical polyp; Cervical smears; Polypectomy; Endometrial pathology

\section{Introduction}

Cervical polyps are the consequences of focal hyperplasia of the columnar epithelium of the endocervical canal. They are seen in approximately $2-5 \%$ of all women [1]. About two-

Received: 2020.06.23. Revised: 2020.08.10. Accepted: 2020.08.31. Corresponding author: Bhabani Pegu, MD

Department of Obstetrics and Gynecology, Jawaharlal Institute of Postgraduate Medical Education and Research (JIPMER), Jipmer Campus Rd., Gorimedu, Puducherry 605006, India

E-mail: bpeguamc@gmail.com

https://orcid.org/0000-0002-5475-7856

Articles published in Obstet Gynecol Sci are open-access, distributed under the terms of the Creative Commons Attribution Non-Commercial License (http://creativecommons org/licenses/by-nc/3.0/) which permits unrestricted non-commercial use, distribution, and reproduction in any medium, provided the original work is properly cited.

Copyright $\odot 2020$ Korean Society of Obstetrics and Gynecology 


\section{Obstetrics \& Gynecology Science}

Vol. 63, No. 6, 2020

thirds of women with cervical polyps are asymptomatic and are diagnosed during routine speculum examination of the cervix $[2,3]$. Although the exact cause of cervical polyps is unknown, postulated etiologies include increased estrogen levels; chronic inflammation of the cervix, vagina or uterus; and clogged blood vessels $[4,5]$. Although most of the cervical polyps are benign, studies from a few decades ago had reported that $0.2-1.7 \%$ of cervical polyps are associated with malignancy [6-8]. An analytical study showed a very low prevalence of malignancy associated with cervical polyp, at approximately $0.1 \%[4,5]$. Hence, it remains unknown whether all cervical polyps, including those in asymptomatic women, should be removed.

The need for performing endocervical and endometrial sampling simultaneously with cervical polypectomy is another controversial issue. A previous study observed that pathological changes in patients with cervical polyps are frequently endometrial in origin [4]. Few studies recommend endometrial sampling in addition to polypectomy irrespective of their symptoms [9-11]. However, according to other studies, polypectomy in cases with asymptomatic polyps was not costeffective and should be recommended only for symptomatic cases $[12,13]$.

With the above background, we conducted this study. The primary objective was to assess the frequency of dysplasia (premalignant) and malignancy in cervical polyps, to determine whether all cervical polyps need to be removed and evaluated histopathologically. The secondary objective was to determine the association among cervical polyp biopsy, cervical smear cytology, and endometrial pathology.

\section{Materials and methods}

This retrospective study was performed in the Women and Child Health department at Jawaharlal Institute of Postgraduate Medical Education and Research (JIPMER), Puducherry, from June 2014 to May 2019.

All patients attending the gynecology outpatient department (OPD), regardless of their presenting symptoms were subjected to a Pap smear test before gynecological examination, as part of screening for cervical carcinoma. Patients diagnosed to have cervical polyps on gynecological examination and exhibiting associated symptoms, including excessive vaginal bleeding or discharge, abdominal mass, or significant findings on pelvic examination, underwent transvaginal ultrasound (TVS) to evaluate endometrial thickness (ET) and other pelvic pathologies. Transabdominal ultrasound (TAS) was performed prior to TVS, if indicated. In women with nonspecific symptoms and incidentally diagnosed cervical polyps, ultrasound was deferred.

In our institute, cervical polyps are usually removed as an outpatient procedure in either of the procedure rooms: in the OPD complex or in the major operation theater (OT) complex. Polypectomy is performed routinely along with endometrial sampling in the same sitting with the help of a pipelle device under local anesthesia regardless of the ET on ultrasound. All specimens are sent to the pathology department for histopathological examination, and patients are advised to return to gynecology OPD for report review 2 weeks after the procedure.

For this study, all cases of cervical polyps were identified from the registers in procedure rooms. Irrespective of symptoms, all cases of cervical polyps in perimenopausal and postmenopausal women, who underwent polypectomy and endometrial biopsy, were reviewed. The perimenopausal group included women aged from 41 years to menopausal age. Postmenopausal status was defined by a period of amenorrhea for more than a year. Women in the reproductive age group, those with a history of gynecological cancers, pregnant women, and women on hormone replacement therapy or oral contraceptives, were excluded from the study. Histopathological reports (HPR) were retrieved from electronic records. Incidental polyps discovered in hysterectomy specimens were excluded from the study. Patients with incomplete data entry in OT register or unavailability of cervical smear cytology reports or histopathological results of the cervical polyp and endometrial biopsy in electronic records were excluded from the study. Fig. 1 shows patient recruitment.

\section{Statistics}

Data were analyzed using a statistical software package, STATA 15.0 (StataCorp, College Park, TX, USA). Histopathological findings were compared between perimenopausal and postmenopausal women. Descriptive statistics, including mean and standard deviation, were calculated for continuous variables such as age. Categorical variables were presented as percentages and frequency. The $\chi^{2}$ or Fisher's exact test was used for comparative statistics according to the number of patients. A $P$-value of $<0.05$ was accepted as statistically significant. 


\section{Obstetrics \& Gynecology Science}

Bhabani Pegu, et al. Evaluation of cervical polyp

\section{Results}

During the study period, polypectomy along with endometrial biopsy was performed for a total of 697 cases of cervical polyps. All cases of cervical polyps in women of reproductive age (335 cases) were excluded from the study.

A total of 139 cases of polypectomy were completed at the minor OT close to OPD, and 223 cases were completed in the procedure room at the major OT complex. Owing to insufficient data entry in the OT register and non-availability of cytology or HPR, only 299 cases of the total 362 cases were included in this study. Of the 299 cases, 216 (72.24\%) cases belonged to the perimenopausal group, and $83(27.75 \%)$ cases belonged to the postmenopausal group. The age range of perimenopausal women in the study was 41-51 years, with a mean of $46.4 \pm 7.5$, and that of the postmenopausal women was $47-64$ years, with a mean of $54.6 \pm 8.5$. A total of $103(34.44 \%)$ cervical polyp cases were symptomatic, of which 74 (24.74\%) were in the perimenopausal group and $29(9.69 \%)$ were in the postmenopausal group.

Cervical polyp histopathology, cervical smear cytology, and endometrial sampling results are shown in Table 1. The com- monest histopathology diagnoses from the cervical polyp in both the groups were benign lesions such as leiomyomatous polyp and endocervical polyp. Premalignant lesions, i.e., cervical intraepithelial neoplasia (CIN), were identified in 6 cases, which accounted for $2 \%$ of all examined polyps. Five out of 6 CIN cases were from the perimenopausal group, and only one case of CIN was from the postmenopausal group. There was only $1(0.33 \%)$ malignant lesion among the examined cervical polyps, which was detected in a postmenopausal woman. In the perimenopausal group, the cervical smear cytology report was normal in 210 (72.23\%) and inflammatory in $6(2 \%)$ cases. Premalignant lesions in cervical smear cytology were identified in 4 (1.33\%) cases, including 3 lowgrade squamous intraepithelial lesions (LSILS) and 1 highgrade squamous intraepithelial lesion (HSIL). All 4 of these premalignant lesions were found in the postmenopausal group. Not a single case of malignancy was observed in cervical smear cytology in both the groups.

In the evaluation of histopathological results for endometrial curettage, the most common findings were normal endometrium $(50.83 \%)$, followed by benign lesion endometrial polyp (21.07\%) in the perimenopausal group. Atrophic and

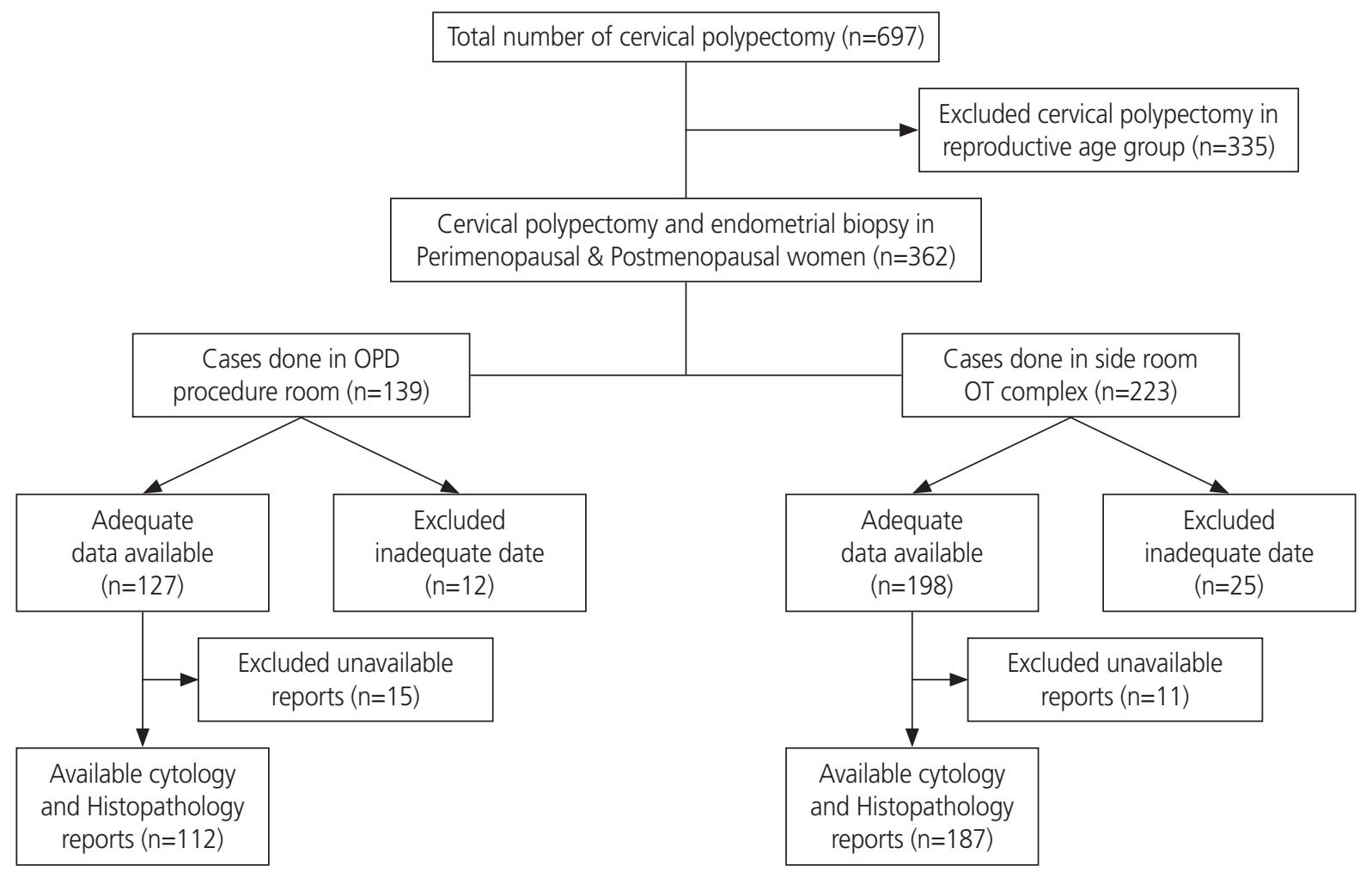

Fig. 1. Flow chart on case recruitment. OPD, outpatient department; OT, Operation Theater. 


\section{Obstetrics \& Gynecology Science}

Vol. 63, No. 6, 2020

endometrial hyperplastic changes were mainly noticed in the postmenopausal group. Only $1(0.33 \%)$ case of endometrial hyperplasia without atypia was noted in the perimenopausal group, whereas $3(1 \%)$ cases of endometrial hyperplasia with atypia and $2(0.66 \%)$ cases of endometrial malignancy were observed in the postmenopausal group.

All malignant findings from HPR of the cervical polyp and endometrial biopsies were from the postmenopausal group. There was no statistically significant association between the menopausal status of the patient and histological results of cervical polyp ( $P=0.224)$, whereas a statistically significant difference was observed between the premenopausal and postmenopausal women in terms of cervical smear cytology reports $(P=0.006)$ and endometrial histological findings $(P=0.000)$.

The majority (65.55\%) of the cases were asymptomatic, incidentally diagnosed with cervical polyp on a routine gynecological examination or presented with other complaints un- related to cervical polyp. Table 2 shows the relation between histopathological results with symptomatic and asymptomatic statuses of the patients. It has been noticed that there was no statistically significant relation between symptomatic status of the patients and malignant status in the cervical smear cytology $(P=0.119)$ and cervical polyp $(P=0.695)$ and endometrial $(P=0.053)$ biopsies.

Table 3 shows the association of histopathological results of cervical polyp biopsy, cervical smear cytology, and endometrial pathologies. All perimenopausal women who were positive for CIN1 in cervical polyp biopsy, had normal findings in cervical smear cytology and endometrial histopathology, except one woman who showed endometrial hyperplasia without atypia in her endometrial biopsy. In one postmenopausal woman, cervical polyp histopathology showed CIN1. Her cervical smear also showed LSIL, and endometrial biopsy revealed malignancy. One case of malignancy was reported in cervical polyp biopsy from a postmenopausal woman, who

Table 1. Histopathological results from cervical polyps, cervical smear cytology, and endometrial pathology of perimenopausal and postmenopausal women

\begin{tabular}{|c|c|c|c|}
\hline Histopathological results & Perimenopausal women & Postmenopausal women & $P$-value \\
\hline Cervical polyp & & & 0.224 \\
\hline Endocervical polyp & $58(19.39)$ & $25(8.36)$ & \\
\hline Leiomyoma & $74(24.74)$ & $30(10.03)$ & \\
\hline Cervical polyp & $41(13.71)$ & $18(6.02)$ & \\
\hline Endometrial polyp & $29(9.6)$ & $5(1.67)$ & \\
\hline Nabothian cyst & $9(3.01)$ & $3(1.00)$ & \\
\hline Malignancy & 0 & $1(0.33)$ & \\
\hline CIN1 & $5(1.67)$ & $1(0.33)$ & \\
\hline Cervical smear cytology & & & $0.006^{a)}$ \\
\hline Normal & $210(70.23)$ & $79(26.42)$ & \\
\hline Inflammatory smear & $6(2.00)$ & 0 & \\
\hline LSIL & 0 & $3(1.00)$ & \\
\hline HSIL & 0 & $1(0.33)$ & \\
\hline Endometrial pathology & & & $0.000^{\mathrm{a})}$ \\
\hline Normal endometrium & $152(50.83)$ & $52(17.39)$ & \\
\hline Endometrial polyp & $63(21.07)$ & $9(3.01)$ & \\
\hline Atrophic changes & 0 & $17(5.68)$ & \\
\hline Hyperplasia & $1(0.33)$ & $3(1.00)$ & \\
\hline Malignancy & 0 & $2(0.66)$ & \\
\hline
\end{tabular}

Values are presented as number (\%).

CIN, cervical intraepithelial neoplasia; LSIL, low-grade squamous intraepithelial lesion; HSIL, high-grade squamous intraepithelial lesion.

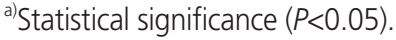




\section{Obstetrics \& Gynecology Science}

Bhabani Pegu, et al. Evaluation of cervical polyp

showed HSIL in cervical cytology. Her endometrial biopsy showed hyperplasia with atypia. Among 3 postmenopausal women, whose cervical polyp histopathology reported benign lesions, 2 cases had premalignant lesions in cervical smear cytology, endometrial biopsy showed hyperplasia with atypia in 2 cases, and one case had malignancy.

\section{Discussion}

Cervical polyps are frequently observed in perimenopausal women; these polyps are usually benign, but their etiology and clinical significance are unclear. In the current study, the leiomyomatous polyp was the most frequent histopathological finding among cervical polyps. In a previous study, chronic inflammation was the most common histological pattern due to the protrusion of the polyp through the external os [5]. Its location may predispose it to ulceration and infection because of exposure to frictional forces and compromised blood flow [14].

Overall, our data revealed that the prevalence of dysplasia $(2 \%)$ and malignancy $(0.33 \%)$ among the histopathological results of cervical polyps. Several studies have reported that none of the removed cervical polyps showed features

Table 2. Significant histopathological findings with respect to symptoms

\begin{tabular}{|c|c|c|c|}
\hline Histopathological findings & Asymptomatic & Symptomatic & $P$-value \\
\hline Cervical polyp & & & 0.695 \\
\hline Benign & $192(64.21)$ & $100(33.44)$ & \\
\hline Premalignant & $4(1.33)$ & $2(0.66)$ & \\
\hline Malignant & 0 & $1(0.33)$ & \\
\hline Cervical cytology & & & 0.119 \\
\hline Normal & $195(65.21)$ & $100(33.44)$ & \\
\hline Premalignant & $1(0.33)$ & $3(1.00)$ & \\
\hline Malignant & 0 & 0 & \\
\hline Endometrial pathology & & & 0.053 \\
\hline Normal endometrium & $152(50.83)$ & $69(23.07)$ & \\
\hline Benign & $42(14.04)$ & $30(10.03)$ & \\
\hline Premalignant & $1(0.33)$ & $3(1.00)$ & \\
\hline Malignant & $1(0.33)$ & $1(0.33)$ & \\
\hline
\end{tabular}

Values are presented as number (\%).

Table 3. Association of cervical polyp histopathology with cervical cytology and endometrial pathology

\begin{tabular}{lcccc}
\hline Cervical polyp histology & Age $(\mathbf{y r})$ & Symptom & Cervical cytology & Endometrial pathology \\
\hline CIN1 & 43 & Menorrhagia & Normal & Hyperplasia without atypia \\
CIN1 & 47 & Asymptomatic & Normal & Normal \\
CIN1 & 41 & Asymptomatic & Normal & Normal \\
CIN1 & 44 & Asymptomatic & Normal & Normal \\
CIN1 & 42 & Asymptomatic & Normal & Normal \\
CIN1 & 59 & White discharge & LSIL & Malignant lesion \\
Malignant & 55 & Postmenopausal bleeding & HSIL & Hyperplasia with atypia \\
Cervical polyp & 56 & Asymptomatic & LSIL & Hyperplasia with atypia \\
Endocervical polyp & 52 & White discharge & LSIL & Hyperplasia with atypia \\
Cervical polyp & 56 & Asymptomatic & Normal & Malignant lesion
\end{tabular}

CIN, cervical intraepithelial neoplasia; LSIL, low-grade squamous intraepithelial lesion; HSIL, high-grade squamous intraepithelial lesion. 


\title{
Obstetrics \& Gynecology Science
}

\author{
Vol. 63, No. 6, 2020
}

of atypia, dysplasia, or malignancy $[12,15,16]$. In a previous study a higher incidence of dysplasia (2.6\%) and atypical/malignancy $(0.30 \%)$ among patients with cervical polyps, which is almost similar to the findings of another author $[17,18]$. A study in 2011 also analyzed 228 cervical polyps and detected dysplasia in 6 (2.6\%) cases without any evidence of malignancy [19]. Table 4 shows the frequency of dysplasia and malignancy in cervical polyps reported by previous studies.

Although the incidence of malignancy in cervical polyps is low, their removal seems clinically prudent for several reasons. There is an increasing evidence of cervical cancer morbidity and mortality due to late presentation; thus, all cervical polyps including those from asymptomatic cases must be removed and subjected to histopathological evaluation so that early dysplastic changes are not missed. We found dysplastic changes and malignant lesions in cervical polyp histopathology, cervical smear cytology, and endometrial biopsy in both asymptomatic and symptomatic cases. A retrospective study reported no premalignant or malignant lesion in patients with asymptomatic cervical polyps [20].

Abnormal cervical smear cytology results can be linked with regeneration or inflammatory processes as well as malignancy. All patients with cervical polyps had undergone cervical smear cytology, and cervical dysplastic changes were found in $1.33 \%$ of cases; most (1\%) of them were postmenopausal women. A study from Turkey included all asymptomatic patients with cervical polyps, and most of them were postmenopausal. They detected cervical dysplasia on cervical cytology only in 1 case $(0.4 \%)$ in premenopausal women [21]. This result was lower than the incidence $(2.6 \%)$ found in 2 other studies $[18,19]$. One of the author reported that the majority of the patients with abnormal previous or concurrent Pap test results had benign endocervical polyps without an evidence of dysplasia or malignancy [18]. These results support the findings of a few previous studies where benign polyps often showed reactive changes, which could have led to atypical cells on a Pap test $[22,23]$. A previous study recommended polypectomy despite normal cervical cytological results [24]. Therefore, if a woman has Pap-test-diagnosed atypical squamous cells of undetermined significance or other premalignant lesions in the context of a cervical polyp, then polypectomy, cervical biopsy, and endometrial and endocervical curettage should be performed as the polyp may explain the atypical cells on the cervical smear test.

In our study, endometrial curettage was performed for all patients who underwent cervical polypectomy, of which 4 cases $(1.33 \%)$ were found to have endometrial hyperplasia and 2 cases $(0.66 \%)$ were diagnosed as having endometrial carcinoma. This incidence was higher in the postmenopausal group than in the perimenopausal group. Other studies that performed endometrial sampling in addition to polypectomy reported endometrial carcinoma rates from $0.1 \%$ to $0.4 \%$ in postmenopausal women with cervical polyps $[25,26]$. Few studies have observed that cervical polyps are often associated with endometrial hyperplasia, which suggests that high levels of estrogen may have a significant etiologic role, and they constitute $4-10 \%$ of all cervical lesions $[2,3]$. However, the necessity of additional endometrial curettage remains controversial. According to a previous study, irrespective of symptomatic or asymptomatic cases, endometrial curettage is not indicated along with cervical polypectomy in premenopausal women. They also stated that symptomatic cervical polyps in postmenopausal women must be excised with mandatory subsequent endometrial curettage since they are significantly associated with severe pathological conditions [10]. Another study also reported that a cervical polyp is 3 times more frequent in patients with endometrial carcinoma. Therefore, curettage must accompany polypectomy [25].

Table 4. Dysplastic and malignant findings of cervical polypectomy reported in previous studies

\begin{tabular}{lcccc}
\hline Author & Year & Sample size & Dysplasia & Malignancy \\
\hline Golan et al. [17] & 1993 & 356 & 2.60 & 0.30 \\
Schnatz et al. [4] & 2009 & 2,548 & 0.50 & 0.10 \\
Buyukbayrak et al. [11] & 2009 & 4,063 & 0.40 & 0.10 \\
Younis et al. [13] & 2010 & 1,126 & 0.20 & - \\
Levy et al. [18] & 2016 & 369 & 2.16 & 0.81 \\
Budak et al. [21] & 2018 & 211 & 1.10 & - \\
Current study & 2020 & 299 & 2.00 & 0.33 \\
\hline
\end{tabular}




\section{Obstetrics \& Gynecology Science}

Bhabani Pegu, et al. Evaluation of cervical polyp

It is well known that genetic (e.g., BRCA1, BRCA2 and Lynch syndrome) and hormonal (e.g., estrogen) factors play a role in the etiology of endometrial hyperplasia and malignancy [27]. Therefore, similar genetic and hormonal factors may also play a role in the etiology of cervical polyps $[11,28]$. Furthermore, endometrial pathologies may exist in the presence of a cervical polyp, irrespective of the presence or absence of symptoms.

There are several limitations to this study. First, its retrospective design limited our ability to analyze the various risk factors and their effects on cervical and endometrial pathologies. Second, the small study population necessitates further prospective research with a larger population. Third, in our setting, ultrasonography, cervical polypectomy, and endometrial sampling are performed irrespective of the menstrual cycle phase unless the patient is menstruating. Hence, we could not correlate the ET with the histopathological findings of either of the procedures as ET varies in accordance with the menstrual cycle phase.

In conclusion, the results of our study demonstrate that premalignant or malignant conditions can often be identified in cervical polyps. We also emphasize the use of cervical smear screening before polypectomy to reveal information regarding the malignancy potential of cervical polyps. Furthermore, performing endometrial sampling along with polypectomy significantly increased the diagnosis of concomitant endometrial abnormalities, especially endometrial hyperplasia and malignancy, which could have been otherwise missed. Hence, we emphasize the importance of routine pathological evaluation of all cervical polyps along with endometrial biopsy, irrespective of the presence or absence of symptoms, so that early detection and treatment can be performed for premalignant lesions and morbidity and mortality due to invasive carcinoma can be reduced.

\section{Conflict of interest}

No potential conflict of interest relevant to this article was reported.

\section{Ethical approval}

Approval for this study was obtained from the JIPMER Scien- tific Advisory and Ethical Committee for human studies (approval number: JIP/IEC/2019/039, dated April 9, 2019).

\section{Patient consent}

A waiver for informed consent was granted because no personal identifying information of the patients was collected.

\section{References}

1. Farrar HK Jr, Nedoss BR. Benign tumors of the uterine cervix. Am J Obstet Gynecol 1961;81:124-37.

2. Khachikyan I, Stratton P. Chapter 40: Benign disorders of the uterine cervix. In: DeCherney A, Nathan L, Goodwin TM, Laufer N, editors. Current diagnosis \& treatment: obstetrics \& gynecology. 11th ed. New York (NY): Lange (McGraw-Hill); 2014. p.657-59.

3. Cortan RS, Kumar V, Collins T. The female genital tract. In: Robbins pathologic basis of disease. 6th ed. Philadelphia (PA): Elsevier; 1992. p.1042-8.

4. Schnatz PF, Ricci S, O'Sullivan DM. Cervical polyps in postmenopausal women: is there a difference in risk? Menopause 2009;16:524-8.

5. Berzolla CE, Schnatz PF, O'Sullivan DM, Bansal R, Mandavilli S, Sorosky Jl. Dysplasia and malignancy in endocervical polyps. J Womens Health (Larchmt) 2007; 16:1317-21.

6. Stenchever MA, Droegemueller W, Herbst AL, Mishell D. Comprehensive gynecology. 4th ed. St. Louis (MO): Mosby; 2001.

7. Tweeddale DN, Gorthey RL, Harvey HE, Tanner FH. Cervical vs. endometrial carcinoma; the relative incidence of cervical carcinoma and endometrial carcinoma. Obstet Gynecol 1953;2:623-8.

8. Mezer J. Metaplasia and carcinoma in cervical polyps. Surg Gynecol Obstet 1942;75:239-44.

9. Long ME, Dwarica DS, Kastner TM, Gallenberg MM, Chantigian PD, Marnach ML, et al. Comparison of dysplastic and benign endocervical polyps. J Low Genit Tract Dis 2013;17:142-6.

10. Stamatellos I, Stamatopoulos P, Bontis J. The role of hysteroscopy in the current management of the cervical polyps. Arch Gynecol Obstet 2007;276:299-303. 


\section{Obstetrics \& Gynecology Science}

Vol. 63, No. 6, 2020

11. Buyukbayrak EE, Karageyim Karsidag AY, Kars B, Sakin O, Alper AG, Pirimoglu $M$, et al. Cervical polyps: evaluation of routine removal and need for accompanying D\&C. Arch Gynecol Obstet 2011;283:581-4.

12. Mackenzie IK, Naish C, Rees CM, Manek S. Why remove all cervical polyps and examine them histologically? BJOG. 2009;116:1127-9.

13. Younis MT, Iram S, Anwar B, Ewies AA. Women with asymptomatic cervical polyps may not need to see a gynaecologist or have them removed: an observational retrospective study of 1126 cases. Eur J Obstet Gynecol Reprod Biol 2010;150:190-4.

14. Israel SL. A study of cervical polyps. Am J Obstet Gynecol 1940;39:45-50.

15. Tirlapur SA, Adeyemo A, O'Gorman N, Selo-Ojeme D. Clinico-pathological study of cervical polyps. Arch Gynecol Obstet 2010;282:535-8.

16. Senturk MB, Budak MS, Durukan OB, Cakmak Y, Yildirim A, Polat M. Clinicopathological evaluations of cervical polyps. Zeynep Kamil Tip Bulteni 2015;46:98-101.

17. Golan A, Ber A, Wolman I, David MP. Cervical polyp: evaluation of current treatment. Gynecol Obstet Invest 1994;37:56-8.

18. Levy RA, Kumarapeli AR, Spencer HJ, Quick CM. Cervical polyps: Is histologic evaluation necessary? Pathol Res Pract 2016;212:800-3.

19. Goldshmid O, Schejter E, Kugler D, Menczer J. Is removal of asymptomatic cervical polyps necessary?: histologic findings in asymptomatic Israeli Jewish women. J Low Genit Tract Dis 2011;15:259-62.

20. Nelson AL, Papa RR, Ritchie JJ. Asymptomatic cervical polyps: can we just let them be? Womens Health (Lond) 2015;11:121-6.

21. Budak A, Kanmaz AG. Role of endometrial sampling in cases with asymptomatic cervical polyps. J Gynecol Obstet Hum Reprod 2019;48:207-11.

22. Kaur J, Dey P, Saha SC, Rajwanshi A, Nijhawan R, Radhika $S$, et al. Cervical cytology in patients with postmenopausal bleeding. Diagn Cytopathol 2010;38:496-8.

23. Cheng RF, Hernandez E, Anderson LL, Heller PB, Shank R. Clinical significance of a cytologic diagnosis of atypical glandular cells of undetermined significance. J Reprod Med 1999;44:922-8.

24. Neri A, Kaplan B, Rabinerson D, Ovadia J, Braslavsky D. Cervical polyp in the menopause and the need for fractional dilatation and curettage. Eur J Obstet Gynecol Reprod Biol 1995;62:53-5

25. Hendricks CH. Polyps: symptoms of cancer? Obstet Gynecol 1955;5:726-7.

26. Fauth C, Franko A, Duan Q, Wood S, Duggan MA. Clinicopathological determinants of vaginal and premalignant-malignant cervico-vaginal polyps of the lower female genital tract. J Low Genit Tract Dis 2011;15:210-8.

27. Coeman D, Van Belle $Y$, Vanderick G, De Muylder X, De Muylder $E$, Campo R. Hysteroscopic findings in patients with a cervical polyp. Am J Obstet Gynecol 1993;169:1563-5.

28. Arslan E, Gokdagli F, Bozdag H, Vatansever D, Karsy M. Abnormal Pap smear frequency and comparison of repeat cytological follow-up with colposcopy during patient management: the importance of pathologist's guidance in the management. North Clin Istanb 2019;6:69-74. 